\title{
Enhanced performance of common electrode materials by means of Atmospheric Plasma Spray coatings
}

\author{
M. Robotti ${ }^{l}$, S. Dosta ${ }^{1}$, M. Gardon ${ }^{\text {, J.M.Guilemany }}{ }^{1}$ \\ M. Kourasi ${ }^{2}$, B. Mellor ${ }^{2}$, R. Wills $^{2}$ \\ ${ }^{\underline{I}}$ Thermal Spray Centre, CPT, University of Barcelona. Martí i Franquès, 1 08028, Barcelona, Spain. E-mail: \\ mrobotti@cptub.eu Telephone: (+34)934031164 \\ ${ }^{2}$ Research Institute for Industry Faculty of Engineering \& the Environment, University of Southampton. SO17 1BJ, \\ Southampton, United Kingdom.
}

\begin{abstract}
Atmospheric Plasma Spray has been used to obtain titanium sub-oxide coatings on steel film, aluminium film, carbon-polymer composite and nickel foam substrates. Substrate roughness had to be increased for boosting the adhesion of the coating on the smooth electrodes, which was especially critical for the fragile carbon-polymer composite. High energetic conditions increased coefficient of thermal expansion mismatch for coating steel and aluminium thin sheets and degraded carbon-polymer composite and nickel foam. Therefore, it was necessary to adjust the spraying parameters towards lower energetic conditions in order to achieve wellbonded and homogeneous coatings on all four different substrates without the presence of cracks in their crosssectional area. The coated materials are investigated for battery electrode applications.

Keywords: titanium sub-oxide, atmospheric plasma spray, electrodes, coatings.
\end{abstract}

\section{Highlights}

- $\quad$ CET mismatch can be effectively controlled for Al and Steel thin sheets.

- Fragile carbon-polymer composites and delicate Ni foams were properly coated.

- Same low energetic spraying conditions successfully coated all electrode materials. 


\section{Introduction}

There is a requirement to develop improved, large-scale electrochemical energy storage devices to gain independency from resource intermittency of renewable technologies, energy distribution or daily fluctuations in consumption [1]. Bi-polar batteries and redox flow batteries are becoming extensively used in systems of electrochemical energy storage and conversion. However, their efficiency and cycle life are strongly subject to chemical stability and bulk resistivity of electrodes, bipolar plates and the contact resistance between them. Cost-effective and rapid manufacturing processes able to coat these materials with electrical conductive and corrosion resistant materials are expected to improve their overall performance. In this way, Atmospheric Plasma Spray (APS) that propels molten particles towards a substrate by means of a plasma jet could be a suitable procedure for carrying it out [2]. As a result, metallic, ceramic or polymeric well-bonded homogeneous coatings are built-up onto a wide variety of pieces in a brief fabrication and it can also be applied as a technique for achieving functional materials [3].

Despite the lack of published articles related to the application of thermal spray processes for the development of battery components, several intellectual properties may be found involving many different electrode materials. M. William et al. in the early 90 s patented a stacked cell array bipolar battery with a thermal sprayed lithium alloy and $\mathrm{FeS}_{2}$ resistant ceramic layer as a container and cell seal [4]. A similar design was purposed by G. Barlow et al. [5]. However, in this case it was not hermetically sealed. The migration of the electrolyte around the bipolar wall and a further formation of ionically conducting paths were prevented by means of a nonwettable material strategically placed around the cells at the periphery of the bipolar walls. A method for fabricating an electrochemical capacitor was developed by L. Bai et al. [6]. The device used bipolar plates made of cobalt, iron or nickel alloys which acted as both the cathode and the substrate upon which the anodes were formed. In one embodiment, this layer could be formed by a bismuth/antimony alloy and deposited by thermal spray with a thickness between 0,1 and 100 micrometers. A similar patent was filed by B. C. Muffoletto et al. 
but a more detailed description of the APS operation conditions was given [7]. H. Ye et al. mentioned that the patent designed by Muffoletto et al. could have significant drawbacks [8]. The thermal instability of certain electrochemically active materials must be taken into account. Particularly, iron disulfide decomposes to FeS at about $550^{\circ} \mathrm{C}$, which is much cooler than the flame temperatures of APS. The undesired decomposition of the active raw material was also handled by J. Dai et al. [9]. In their work, the feedstock was a mixture comprising an effective quantity of a source of a thermally protective salt, $\mathrm{LiCl}$ or $\mathrm{LiBr}$, and nano- or microstructured active materials like sulfides. This mixture was sprayed onto 304 stainless steel and graphite. It was believed that the thermally protective salt prevented the decomposition of the active material by providing cooling via the heat of fusion. The energy associated with the fusion of the salt acts to cool the active material particles and thus prevent their thermal dissociation. Sulfur is a good choice for preventing the powder degradation due to it being a poor heat conductor and slowing the heating of the pyrite particles as other authors previously reported. However, J. Dai et al. assure that thermally protective salt has a number of advantages over sulfur: the combination of the salt with the active material avoids leaching with flammable carbon disulfide; the amount of salt may be adjusted to control final porosity of the coating and the salt can function as an electrolyte, which is useful from an electrochemical performance standpoint. Nonetheless, same authors also added sulfur in the elemental feedstock in a following patent with the same purpose [10]. More recently, D. Batson designed a bipolar battery electrode structure and the sealed bipolar battery assembly [11]. In this case, electrode substrates and bipolar walls were configured as circular areas. A thermoplastic layer material was applied by thermal spray with the purpose of electrically insulating the outer surface of the battery. However, in this case the active components of the device were not obtained as coatings by any process related to thermal spray technologies.

Thermal spray processes have been also widely used as a technique for developing electrode materials in Solid Oxide Fuel Cells (SOFC) and many scientific contributions were published. In these devices, an electrochemical conversion is carried out producing electricity directly from oxidizing a fuel, in addition a solid oxide or a ceramic are used as electrolytes. Despite the materials involved do not perform in the same environment than 
those electrodes in standard, bi-polar or mobile batteries, is worthy to review some of the chosen experimental procedures during the last years. $\mathrm{H}$. Nie et al. produced strontium-doped $\mathrm{LaMnO}_{3}$ perovskites (LSM) as cathodes for SOFC [12]. A certain decrease in the electric conductivity was found due to the porous structure of the APS coating when compared to the LSM bulk sample. However, at $800^{\circ} \mathrm{C}$ it met the conductivity requirements of the cathode for high temperature SOFC. Moreover, this porosity favored air/ $\mathrm{O}_{2}$ transportation to reaction sites and lowered the cathodic polarization. It was finally concluded that APS appeared as a plausible technique for obtaining porous LSM cathodes with good performances. On the other hand, anode layers for SOFC built-up by APS using different feedstocks were studied by D. Hathiramani et al. [13]. To end up with a high electrochemical activity, $\mathrm{NiO}$ and $\mathrm{Y}_{2} \mathrm{O}_{3}$-stabilized zirconia were milled to a particle size bellow 1 micron and then agglomerated below 80 microns. This manufacturing method provided powders with very good properties but with lower flowabilities. Then, feedstock was mixed with commercial available materials. The results showed no difference between the submicron-sized powders and those NiO and YSZ with larger grain sizes but it was observed a better thermal cycle resistance when the anodes were produced by separately injecting $\mathrm{NiO}$ and $\mathrm{YSZ}$ powder into the plasma plume. O. Kwon et al. also worked in this line [14]. It was compared spraydried nano- and microsized $\mathrm{NiO}$ and YSZ powders spraying at different $\mathrm{Ar} / \mathrm{H}_{2}$ ratios. The mechanical properties and electrical conductivity of the coatings were strongly dependent on the nature of the powder feedstock. Those coatings built-up from spraydried powders contained a nanosized phase distribution and more three-phase boundaries, which lead to a higher electrical conductivity due to the more uniform distribution of the phases throughout the coatings when compared to the microsized feedstock. An increase of hydrogen in the plasma jet must be also taken into account because it had the capacity of lowering the electrical conductivity of the anode. More recently, J. M. Guilemany et al. used APS to produce all the components of a SOFC: Anode (YSZ-NiO), Cathode (LSM) and Electrolyte (YSZ) [15]. The three layers were properly assembled and adhered due to an on-time gradual transition of the materials during the spraying. 
It should be noted that these previous examples of the use of thermal spray technologies in energy storage devices are limited to the application of non-conductive seals or for the application of active materials in a morphologically attractive form. Reduced stoichiometries of titanium dioxide $\left(\mathrm{TiO}_{2-\mathrm{x}}\right)$ are well known due to its characteristics and properties. The electrical conductivity in combination with the chemical resistance of this material is of interest for many applications in electrochemistry [16]. In this work, different substrates such as steel, aluminium, carbon polymer composite and nickel foam commonly applied as electrodes in batteries have been coated by reduced stoichiometries of titanium dioxide using Atmospheric Plasma Spray. Electrochemical performances of each coated piece have been compared with the original commercial uncoated samples.

\section{Materials and Experimental Details}

Feedstock powder comprising rutile $\mathrm{TiO}_{2}$ doped with Magnéli phases $\mathrm{Ti}_{8} \mathrm{O}_{15}$ and $\mathrm{Ti}_{9} \mathrm{O}_{17}$ (Sulzer Metco) was sprayed using an APS A-3000S system with an F4 plasma torch (Sulzer Metco, Germany). Particle size distribution was measured by Laser Scattering (LS Beckman Coulter). Substrate materials were: i) steel film (thickness $0,5 \mathrm{~mm}$ ), ii) aluminum film (thickness: $1 \mathrm{~mm}$ ) iii) carbon-polymer composite (thickness: $4 \mathrm{~mm}$ ) and iv) nickel foam (thickness: $1 \mathrm{~mm}$, diameter of Ni network: 80 microns). Substrates were cleaned before the spraying process by means of an ultrasonic equipment (Ultrasons-HD, J.P. Selecta) and acetone (Panreac) and their roughness was measured by a profilometer (SJ-210, Mitutoyo). Cross-section area of the coatings was studied by Scanning Electron Microscopy, SEM (ProX Phenom). Coated samples were cut and mounted in a conductive phenolic resin (Konductomet, Buehler) followed by the metallographic preparation. Electrolytes for electrochemical characterization of the electrodes were made using deionized water obtained from a Purite water purifier. $\mathrm{KOH}$ and $\mathrm{H}_{2} \mathrm{SO}_{4}$ were used as received from Sigma Aldrich. Electrochemical measurements were taken in a standard two-compartment glass electrochemical cell using an Autolab potentiostat/galvanostat operating with GPES acquisition software. Potentials were measured against a saturated calomel reference electrode (SCE) and a platinum counter electrode was used. Measurements were taken at $20^{\circ} \mathrm{C}$ electrolytes were 
de-oxygenated using a vigorous stream of $\mathrm{N}_{2}$ gas. Battery measurements were obtained using an MTI BST8WA battery analyser operating with MTI TC5.3 operating software.

\section{Results and Discussion}

\section{$\underline{3.1 \text { Coating development }}$}

In a previous work, the authors presented APS manufactured $\mathrm{TiO}_{2-\mathrm{x}}$ coatings as a novel method for preparing electrode surfaces [17]. Coated samples exhibited good mechanical properties regarding their microhardness and adhesion to steel substrates. In both acid and alkali environments it was found an increased potential range of operation compared to uncoated stainless steel electrodes. Besides this, coated samples showed higher electrical conductivity in a simulated lead flow battery compared to the most commonly used carbon-polymer electrodes as commercial standard material. Atmospheric Plasma Spray involves high temperatures [2]; therefore, the interaction of each different substrate material with the molten particles and the plasma jet may carry out very distinct results. This is especially emphasized in the coefficient of thermal expansion (CTE) mismatch during the spraying. In this way, operation conditions may be adjusted to provide a satisfactory performance of the obtained coating. Besides this, as it has been reported before [18], the composition of the plasma causes a different degree of oxidation to $\mathrm{TiO}_{2}$ coating, namely, the formation of distinct amounts of oxygen vacancies in its crystal lattice, which leads to a range of electric resistivities. Thus, neither $\mathrm{Ar} / \mathrm{H}_{2}$ ratios nor plasma intensity were altered in this study and the composition of the coating was remained constant based on $\mathrm{TiO}_{2}$ rutile and Magnéli phase $\mathrm{Ti}_{8} \mathrm{O}_{15}$. Figure 1 shows the XRD results of each substrate material. The previously prepared APS coatings used a relatively heavy-duty steel substrate, having a thickness of $6 \mathrm{~mm}$ [17]. Although this was sufficient to prove the concept of electrode manufacture, it is not practical to use such substantial substrates for many battery applications. The results presented in this paper focus on optimising the coating process to enable truly lightweight, corrosion resistant electrode materials. In this regard, four further 
substrates were investigated and are detailed in table 1 . The steel and aluminium were chosen specifically due to their instability in typical battery environments. It is essential that for these materials the spray coating process does not perforate or deform the substrate from its original geometry. Furthermore, for the nickel foam, a coating covering all surfaces throughout the porous structure is required.

\begin{tabular}{|l|c|c|}
\hline Substrate & Thickness $[\mathbf{m m}]$ & Density $\left[\mathbf{g} / \mathbf{c m}^{3}\right]$ \\
\hline Steel foil & 0.5 & 7.84 \\
\hline Aluminium plate & 1.0 & 2.70 \\
\hline Carbon/polymer composite & 4.0 & 1.85 \\
\hline Nickel foam & 1.0 & 0.45 \\
\hline
\end{tabular}

Table 1: Thickness and density of the spray-coated electrodes

\subsubsection{Steel substrates}

In this survey, the starting powder was based on $\mathrm{TiO}_{2}$ rutile and Magnéli phases $\mathrm{Ti}_{8} \mathrm{O}_{15}$ and $\mathrm{Ti}_{9} \mathrm{O}_{17}$. The particles had an irregular morphology and their size distribution range was $-45+15 \mu \mathrm{m}$. Substrates were subjected to ultrasonic cleaning with acetone during $10 \mathrm{~min}$ in order to remove dirt and impurities present on the surface. Then, the metallic pieces were sprayed using operation conditions previously described [17] and can be understood in this study as high energetic conditions (HEC). With initial preparations, however, the coatings were not satisfactorily bonded, which was attributed to the smooth surface of the electrode materials. Molten particles did not anchor at the point of the impact, which resulted in poor adhesion during the re-solidification of the particle. Therefore, the metallic pieces were homogeneously grit-blasted by a stream of 5 bar of compressed air containing alumina particles with an approximate particle diameter of $700 \mu \mathrm{m}$. Surface roughness $\left(\mathrm{R}_{\mathrm{a}}\right)$ was increased from $0,47 \mu \mathrm{m}$ to $6,87 \mu \mathrm{m}$. Subsequently, the samples were cleaned and sprayed following same above procedure. Coatings were successfully built-up and their cross-section area was studied by SEM (figure 2a). In 
spite of having $\mathrm{TiO}_{2-\mathrm{x}}$ deposited onto the substrate, the coating exhibited an almost complete decohesion from steel surface. Moreover, a considerable number of vertical cracks were also observed. CTE mismatch between metal oxide coating and metallic substrate may result in considerable accumulation of residual stress, which develops either cracks or delamination of the coating. Two actions were carried out with the purpose of avoiding this. First, nitrogen was utilised to refrigerate the metallic substrates. Then, starting stand-off distance (D0) was increased from 40 to 60 and finally $80 \%$ (D1, D2, D3 respectively). Significant differences were obtained as long as the spraying distance was enlarged. Samples sprayed at D2 and D3 distances were satisfactorily bonded without the presence of cracks or delamination between layers. A slight proportional decrease in thickness was also observed from D0 to D3. Both consequences could be based on the temperature of the particles, which is reduced for larger in-flight times and distances. Therefore, particles at lower temperature impacting onto steel, together with $\mathrm{N}_{2}$ cooling, contribute to avoid CTE mismatch leading to less residual stress and cracking. Decrease in thickness could be attributed to lower deposition efficiency when spraying the metal oxide particle at lower temperatures. These spraying conditions can be considered as low energetic conditions (LEC). Figure 2b shows a proper bonded APS $\mathrm{TiO}_{2-\mathrm{x}}$ coating using LEC.

\section{$\underline{\text { 3.1.2 Aluminium substrates }}$}

Following development of the spray coating process using stainless steel substrates, aluminium was then used to demonstrate that the APS $\mathrm{TiO}_{2-\mathrm{x}}$ coating provides a functional and corrosion resistant layer for lightweight electrodes. In this case, substrates were also grit-blasted to a $R_{a}$ of $6,23 \mu \mathrm{m}$ and again the samples were adequately cleaned before the coating process. Comparable CTE made to spray directly with LEC instead of beginning with HEC [19]. After characterizing cross-section area of the coatings, it was observed that the samples did not exhibit cracks and were well adhered to the metal substrate (figure 3).

\subsubsection{Carbon-polymer composite substrates}


Electrodes based on carbon-polymer composites are attractive due to its moderate corrosion resistance and low weight. Carbon corrosion at more positive potentials, for example in metal-air batteries and fuel cells, is a well known phenomena, however, and a protective layer such as the APS coating would have significant benefits in these applications. This material is composed by a blend of different polymers with conductive carbon black. Bulk electrodes can be obtained by isostatic pressing. Therefore, develop enough roughness on smooth composite material was critical because of its fragile inner granular structure (figure 4). Grit-blasting broke the substrate at high (standard) pressures. Thus, it was decreased down to 2 bar with the purpose of preventing that the substrate could break again. Impacting alumina particles did not deform plastically the composite, but removed very quickly polymer and carbon material. Finally, $\mathrm{R}_{\mathrm{a}}$ of 5,69 $\mu \mathrm{m}$ was obtained and damages in the overall substrate structure were not found. Due to the novelty of this composite in thermal spray technologies, both HEC and LEC were tested. Firstly, energetic conditions were carried out and the metal oxide coating was successfully built-up. However, stress accumulated in the contact between the composite and the metallic support while thermal spraying, led to localized fissures in the substrate and eventually fragmented the sample. Thus, LEC were selected and APS metal oxide layers were properly bonded lacking fractures where the composite piece was fixed. Coating was well adhered to the composite without the presence of vertical or horizontal cracks.

\section{$\underline{3.1 .4 \mathrm{Ni} \text { foam }}$}

$\mathrm{Ni}$ foams have also drawn considerable attention because of their relative high specific surface areas compared to planar electrode materials. Despite the internal complexity of the net, APS technology may be used for coating non-planar pieces, namely, 3D-geometries such as foams. No alteration of the substrate surfaces was done due to the impossibility to increase roughness to this material by means of grit-blasting process. Consequently, samples were directly sprayed after ultrasonic cleaning with acetone. HEC dramatically damaged 
the filaments of the foams and the structure was practically useless for the final application. On the other hand, LEC homogeneously coated the Ni foam. Figure $5 \mathrm{a}$ and $5 \mathrm{~b}$ show uncoated and coated foam respectively. Besides this, cross-section of APS $\mathrm{TiO}_{2-\mathrm{x}}$ coatings did not show cracks and were well-bonded onto the nickel surface. However, filaments were just coated on one side. Therefore, both sides of the Ni foam were coated and a complete layer of $\mathrm{TiO}_{2-\mathrm{x}}$ rounded the material (figures $5 \mathrm{c}$ and $5 \mathrm{~d}$ ).

\subsection{Electrochemical analysis}

Cyclic voltammetry was used to assess the potential range over which the substrates and spray coated electrodes were electrochemically stable. The voltammetry was performed in sulphuric acid and potassium hydroxide electrolytes to simulate conditions within typical battery environments (e.g. lead acid and NiMH). The potentials were cycled between oxygen evolution and hydrogen evolution regions. Each of the coated substrates displayed similar electrochemical responses. The voltammograms obtained for the stainless steel and coated stainless steel are presented in Figure 6 . The figure presents the $4^{\text {th }}$ consecutive voltammogram. In acidic media, figure $6 \mathrm{a}$, the uncoated, stainless steel substrate showed significant oxidation currents commencing at circa 1.0 V vs. SCE, corresponding to corrosion of the stainless steel (likely due to the $\mathrm{Fe}^{2+} / \mathrm{Fe}^{3+}$ redox couple). At more positive potentials bulk oxygen evolution can be seen at $1.5 \mathrm{~V}$ vs. SCE. At negative potentials, hydrogen evolution was observed at potentials more negative than $-0.7 \mathrm{~V}$ vs. SCE. The coated stainless steel shows a voltammetric response typical for Magneli phase materials. Towards positive potentials, oxygen evolution commences at circa $2.0 \mathrm{~V}$ vs. SCE. Towards negative potentials, hydrogen evolution commences at circa $-1.0 \mathrm{~V}$ vs. SCE. Between -1.0 and $-0.2 \mathrm{~V}$ vs. SCE some reversible redox activity of the titanium sub-oxides can be seen. This is in agreement with previous literature studies [20]. Repeated voltammograms on the same electrode did not show any shift in the electrochemical response. Moreover, it is important to note that no electrochemical features associated with the underlying stainless steel were observed, which suggests that the coating forms a satisfactory electrochemically isolating barrier between the electrolyte and substrate. The voltammogram suggests that the electrode would be suitable for use in this acid electrolyte between voltages of -1 and $+2 \mathrm{~V}$ vs. 
SCE. Figure $6 \mathrm{~b}$ presents the cyclic voltammograms obtained in the $\mathrm{KOH}$ electrolyte. In this media, the stainless steel substrate showed a small redox reaction $0.3 \mathrm{~V}$ vs. SCE, which is likely to be caused by one of the alloying materials. At more positive potentials, commencing at $0.4 \mathrm{~V}$ vs. SCE, there a sharp oxidation wave associated with corrosion and oxygen evolution. The coated stainless steel, however, displayed the expected response for titanium sub-oxides in an alkaline electrolyte [20] and demonstrates that the coating substantially protects the underlying aluminium from corrosion.

\subsection{Proof of concept lead acid battery}

A parallel plate single cell lead acid battery was constructed to demonstrate the suitability of the spray-coated electrodes in a functional device. Positive (PAM) and negative (NAM) active material was removed from the lead grids of a commercial $2 \mathrm{~V}$ Cyclon D-cell via mechanical scraping. The powdered PAM and NAM was then layered manually onto the aluminium spray coated substrates (Figure 7) to produce the battery electrodes. Electrical contact to the active material was simply made through contact, which is non-ideal and introduced significant voltage losses, particularly at high charge/discharge rates. Nevertheless, the cell provided a good test piece to provide proof-of-concept operation for the novel electrodes. The positive and negative electrode each had dimensions of $9.9 \mathrm{~cm} \times 5 \mathrm{~cm}$ and incorporated $20 \mathrm{~g}$ of active material. AmerSil FF60 was used as the interelectrode separator. 1.29 s.g. sulphuric acid was used as the electrolyte. The cell was cased in a polypropylene wrap. The overall cell had dimensions of $10 \mathrm{~cm}$ x $5.6 \mathrm{~cm}$ x $0.6 \mathrm{~cm}$ giving an overall volume of $33.6 \mathrm{~cm}^{3}$ (Figure 8). The mass of the cell was $166 \mathrm{~g}$, giving a density of $4.9 \mathrm{~g} \mathrm{~cm}^{-3}$. The cell was subjected to a number of constant current charge discharge cycles using cell cut off voltages of $2.6 \mathrm{~V}$ during charge periods and $1.2 \mathrm{~V}$ during discharge periods. The current was varied between 100 and $1000 \mathrm{~mA}$. Figure 8 presents a typical charge/discharge cycle at $100 \mathrm{~mA}$ constant current throughout. At this current density, the charge efficiency was $>98 \%$ and the cell delivered a capacity of $1500 \mathrm{mAh}$. At higher currents, the charge efficiency remained high, however the capacity decreased markedly. Table 2 presents dropped to $180 \mathrm{mAh}$ when the cell was operated at $1000 \mathrm{~mA}$. This reduction in the capacity is predominantly due to the high contact resistance and IR drop 
between the paste and the electrode surface associated with the use of second hand PAM and NAM. This could be overcome by using paste formulated and applied specifically to these electrodes. Despite the limited current, the cell still returned an energy density of $9 \mathrm{Ah} \mathrm{kg}^{-1}$ or $45 \mathrm{Ah} \mathrm{L}^{-1}$ at $100 \mathrm{~mA}$ current draw.

\begin{tabular}{|l|c|}
\hline Current, mA & Capacity, mA hr \\
\hline $\mathbf{1 0 0}$ & 1500 \\
\hline $\mathbf{2 5 0}$ & 1100 \\
\hline $\mathbf{5 0 0}$ & 630 \\
\hline $\mathbf{7 5 0}$ & 350 \\
\hline $\mathbf{1 0 0 0}$ & 180 \\
\hline
\end{tabular}

Table 2: Capacity as a function of discharge for the demonstration battery using spray coated aluminium electrodes.

\section{Conclusions}

Four different lightweight and corrosion resistance materials such as steel film, aluminium film, carbon-polymer composite and nickel foam were coated by Atmospheric Plasma Spray (APS) technology. Smooth initial surfaces had to be mechanically modified in order to increase the roughness and easing the adhesion of the molten particles. Spraying conditions were properly chosen with the purpose not to damage the substrates and to control the influence of the coefficient of thermal expansion (CTE). The coated substrates were electrochemically assessed using cyclic voltammetry to confirm that the coating provided an electrochemically isolating but electrically conductive layer, which protected the underlying substrate from contact with the electrolytes. A proof-of-concept $2 \mathrm{~V}$ single cell lead-acid battery was constructed using aluminium as substrate 
and LEC spraying conditions which gave well-bonded homogeneous $\mathrm{TiO}_{2-\mathrm{x}}$ layers. The battery returned an energy density of $9 \mathrm{Ah} \mathrm{kg}^{-1}$ or $45 \mathrm{Ah} \mathrm{L}^{-1}$ when operated using a current of $100 \mathrm{~mA}$. Further work will be undertaken to improve the electrical contact between the PAM/NAM and electrode to enable high current operation. This work highlights the versatility of APS technology, the lightweight of utilised substrates, the lowcost of used feedstock and the possibility to spray onto 3D-geometry substrates with high specific surface. Moreover, this spraying technology fits in the scale-up of these products because of short deposition times, electrochemical results and finally because of the fundamental proof of experimental coatings inside a real acid battery.

\section{Acknowledgments.}

The authors wish to thank Generalitat de Catalunya (2014 SGR1558) and Ministerio de Economía y Competitividad del Gobierno de España (MAT2013 46755R) for the financial support for this research project.

\section{References}

[1] M. Semadeni. Storage of Energy, Overview. Encyclopedia of Energy (2004) pp. 719.

[2] L. Pawlowski. Science and Engineering of Thermal Spray Coatings. John Wiley \& Sons, Chichester, U.K., 1995.

[3] M. Gardon, J M. Guilemany. J. Mat. Sci.: Mat. Elec. (2012) DOI: 10.1007/s10854-012-0974-4.

[4] M. T. Williams, J. D. Briscoe, S. M. Oweis. United States Patent 5.254.415 (1993).

[5] G. Barlow, S. J. Specht. United States Patent 5.411.818 (1995).

[6] L. Bai, J. G. Kincs, M. Chason. United States Patent 5.568.353 (1996).

[7] B. C. Muffoletto, W. M. Paulot, J. E. Spaulding. United States Patent 5.716.422 (1998).

[8] H. Ye, C. Strock, T. Xiao, P. R. Strutt, D. E. Resiner. International Patent WO 99/64641 (1999). 
[9] J. Dai, R. A. Guidotti, T. D. Xiao, D. E. Reisner. United States Patent 6.794.086 B2 (2004).

[10] R. A. Guidotti, H. Ye, T. D. Xiao, D. E. Reisner, D. H. Doughty. United States Patent 6.926.997 B2 (2005).

[11] D. Batson. United States Patent US2008/0090146 A1 (2008).

[12] H. Nie, W. Huang, T. Wen, H. Tu, Z. Zhan. J. Mat. Sci. Let. 21 (2002) 1951-1953.

[13] D. Hathiramani, R. Vaben, D. Stöver, R. J. Damani. J. Therm. Spray Tech. 15, 4 (2006) 593-597.

[14] O. Kwon, S. Kumar, S. Park, C. Lee. J Pow. Sour. 171 (2007) 441-447.

[15] J. M. Guilemany, M. Torrell, I. G. Cano, J. Fernández. Inter. Therm. Spray Conf. proc. (2012) Houston, USA.

[16] S. Andersson, B. Collen, U. Kuylenstierna, A. Magnéli Acta Chem. Scand, 11 (1957), p. 5.

[17] M. Gardon, S. Dosta, J. M. Guilemany, M. Kourasi, B. Mellor, R. Wills. J Pow. Sour. 238 (2013) pp. 430434.

[18] M. Gardon, J. M. Guilemany. Inter. Therm. Spray Conf. proc. (2012) Houston, USA.

[19] http://www.matweb.com/ (accessed 07/04/2013).

[20] R.G.A.Wills, F.C. Walsh. Electrochim. Acta. 55 (2010), 6342.

\section{List of figure captions}

Figure 1. X-Ray Diffraction spectrum of: a) steel, b) aluminum, c) carbon-polymer composite and d) nickel foam.

Figure 2. SEM micrograph: a) APS $\mathrm{TiO}_{2-x}$ coating on steel film obtained by HEC and b) APS TiO2-x coating on steel film obtained by LEC.

Figure 3. SEM micrograph: APS $\mathrm{TiO}_{2-x}$ coating on aluminium film obtained by LEC

Figure 4. a) (Above) APS TiO ${ }_{2-x}$ coating on carbon-polymer composite obtained by LEC (SEM micrograph). b) (Below) Carbon-polymer composite structure (OM micrograph). 
Figure 5. a) Ni foam, b) Ni foam coated by APS $\mathrm{TiO}_{2-x}$, c) longitudinal cross-section area of a coated filament and d) transversal cross-section area of a coated filament.

Figure 6. Cyclic voltamograms obtained at a) APS coated stainless steel [red line] and stainless steel substrate [black line] from an acid electrolyte comprising $1.0 \mathrm{~mol} \mathrm{dm}^{-3} \mathrm{H}_{2} \mathrm{SO}_{4}$ and b) APS coated stainless steel [red line] and stainless steel substrate [black line] from an acid electrolyte comprising $4.0 \mathrm{~mol} \mathrm{dm}{ }^{-3} \mathrm{KOH}$ at $295 \mathrm{~K}$.

Potentials recorded using a sweep rate of $50 \mathrm{mV} \mathrm{s} \mathrm{s}^{-1}$ vs. an SCE reference. Working electrode area $=1.13 \mathrm{~cm}^{2}$.

Figure 7. Aluminium spray coated substrates to produce the battery electrodes.

Figure 8. Overall cell with dimensions of $10 \mathrm{~cm} \times 5.6 \mathrm{~cm} \times 0.6 \mathrm{~cm}$.

Figure 9. Typical charge discharge cycle from the lead acid test battery. Charge and discharge performed at a constant current of $100 \mathrm{~mA}$. Cell voltage cut offs were set at $2.6 \mathrm{~V}$ during charge and $1.2 \mathrm{~V}$ on discharge. 


\section{List of figures}

Fig. 1

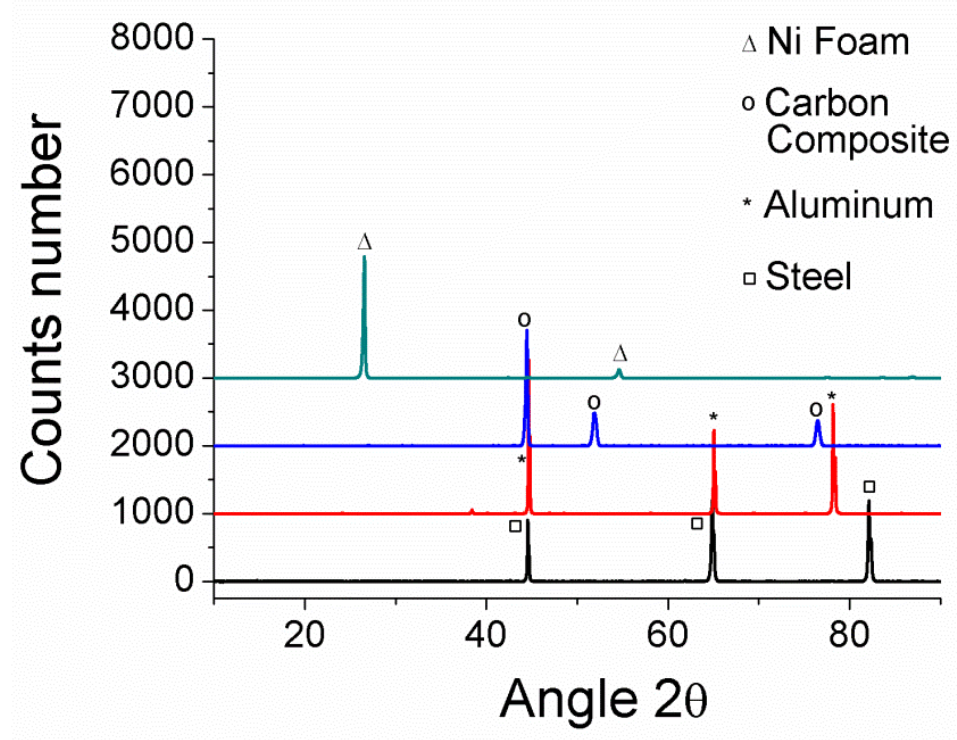

Fig. 2
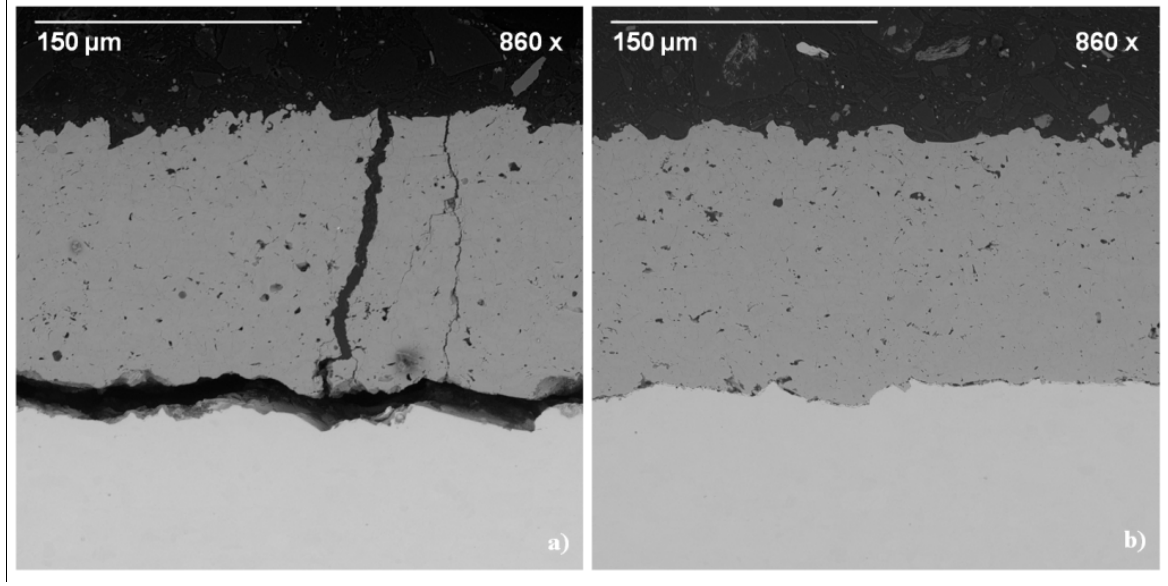
Fig. 3

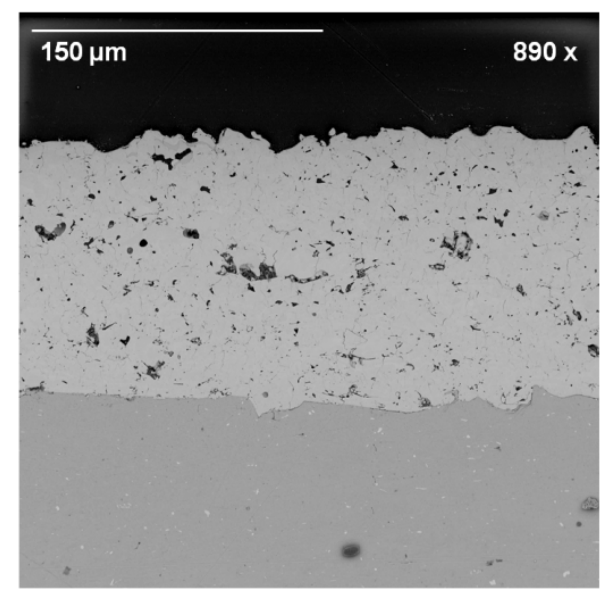

Fig. 4
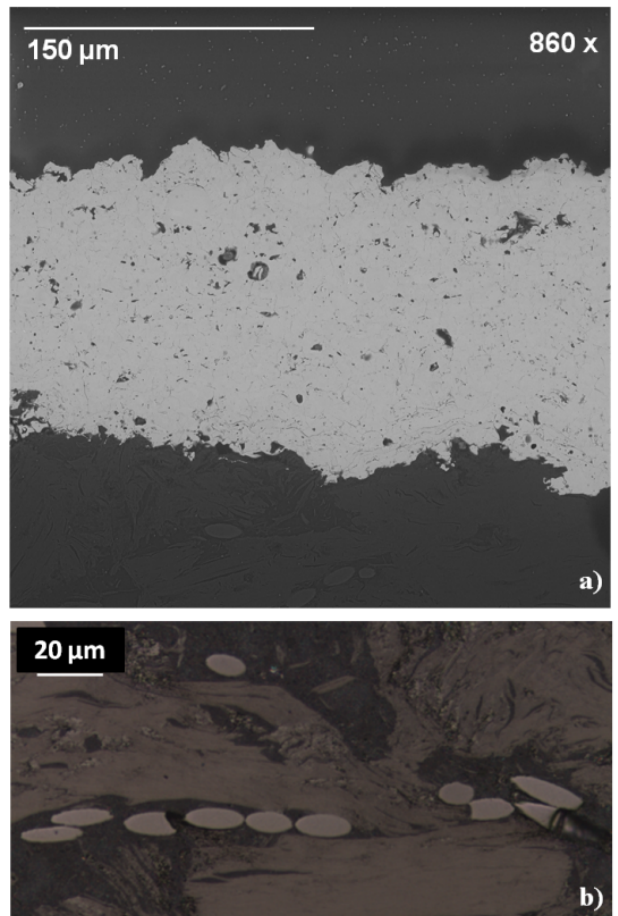
Fig. 5
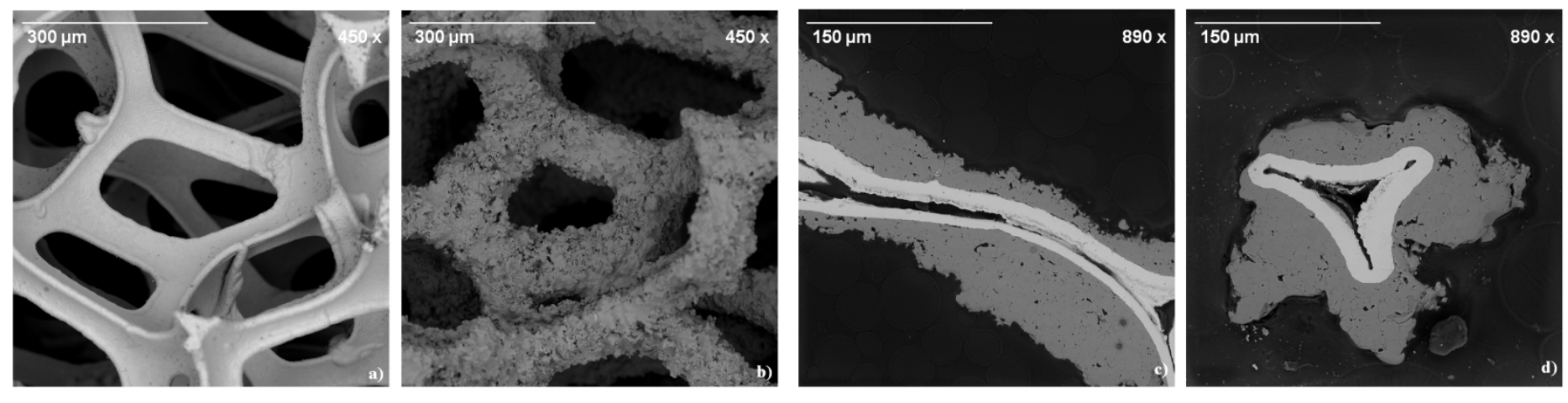

Fig. 6

A

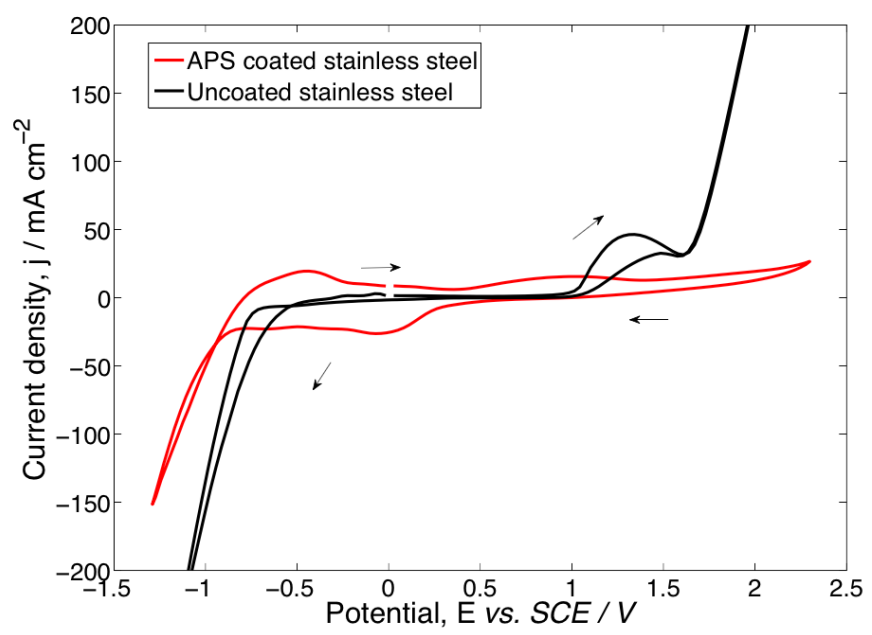

B

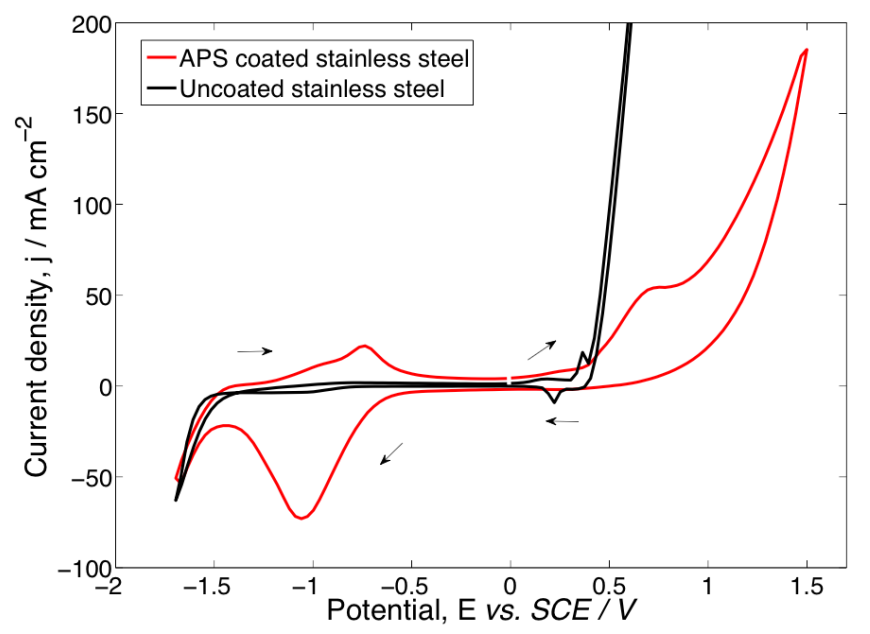


Fig. 7

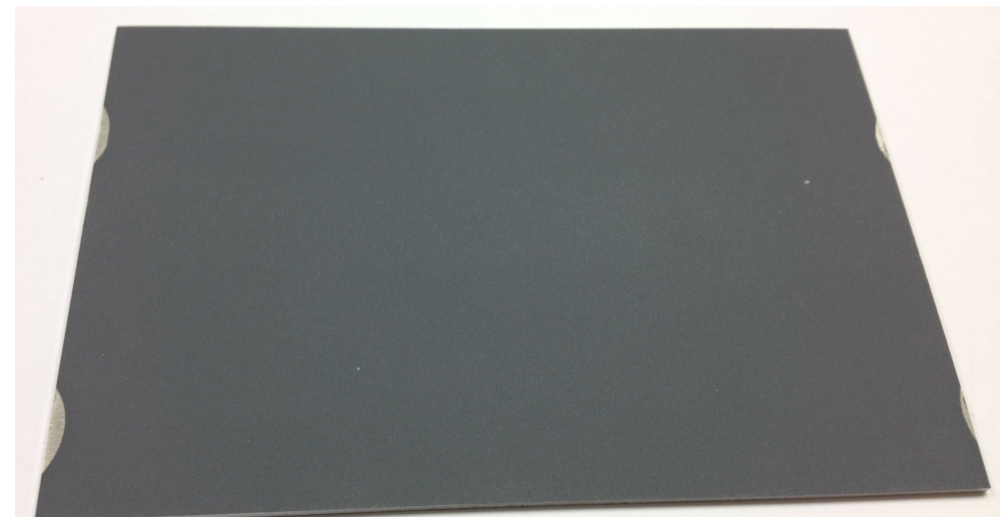

Fig. 8

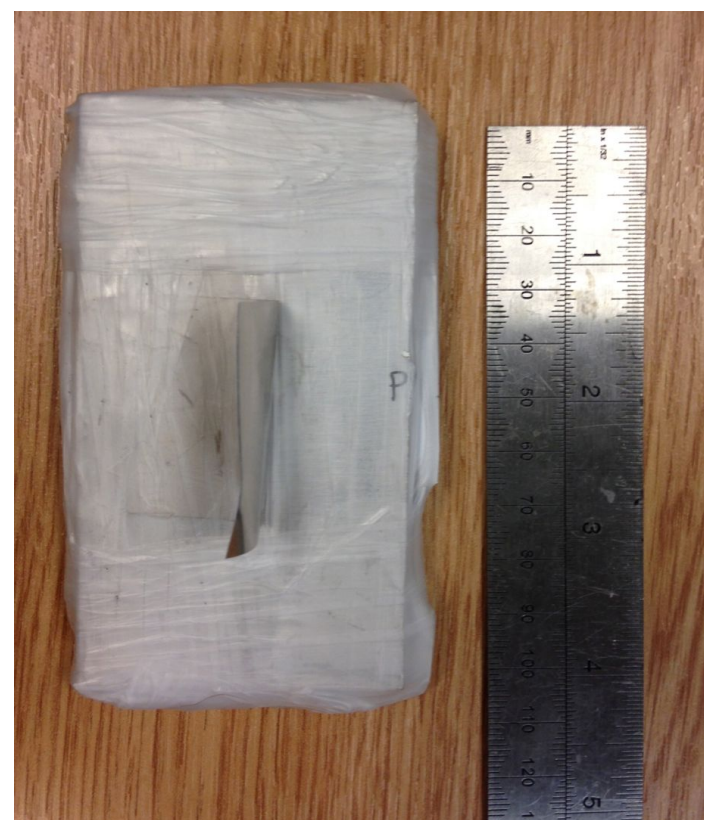


Fig 9

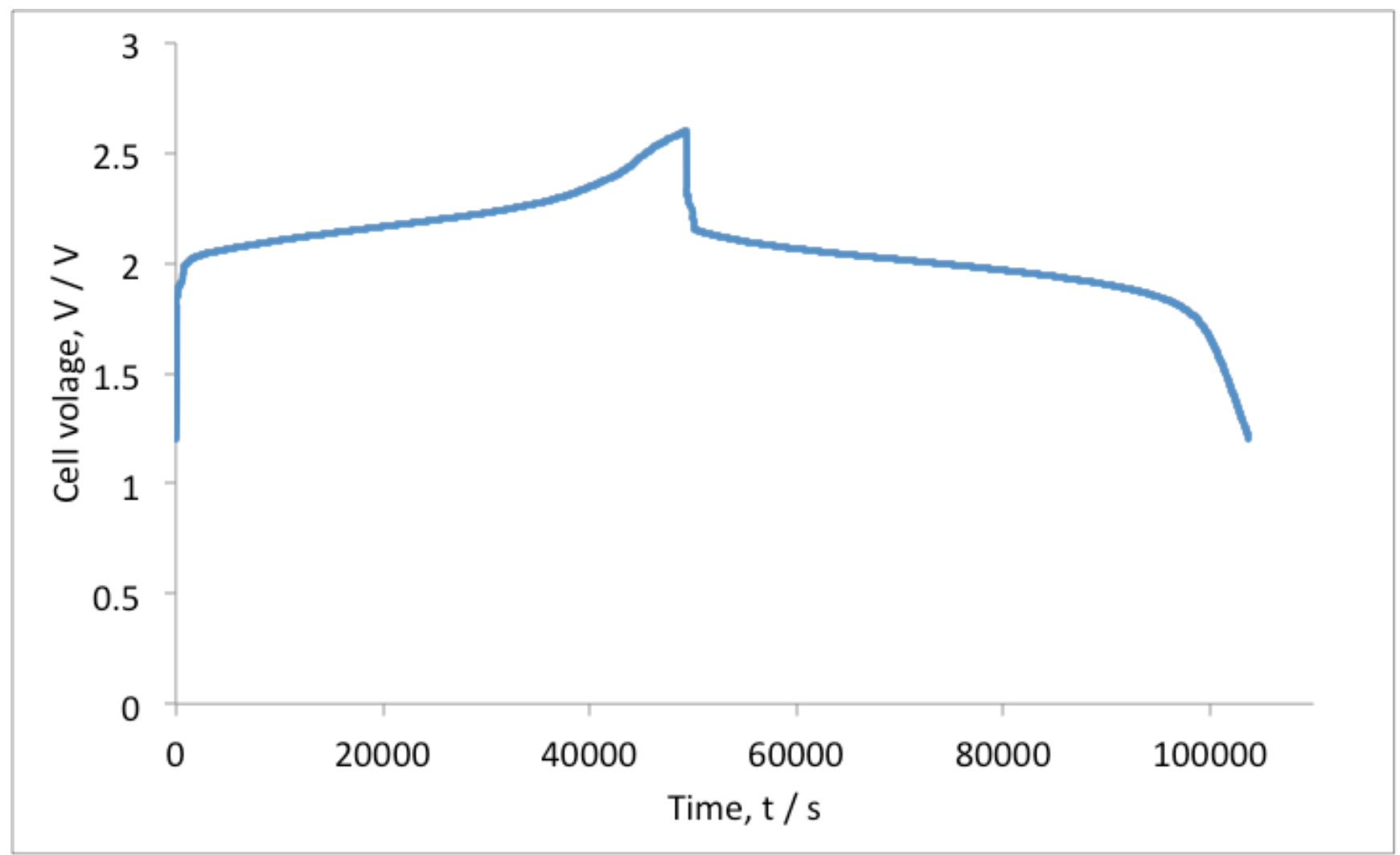

